\title{
CONCEPÇÕES DE PROFESSORES DE CIÊNCIAS DA NATUREZA NO CONTEXTO DA HISTÓRIA E FILOSOFIA DA CIÊNCIA
}

\author{
ANTONIO MARCOS DE SOUZA* \\ JOSANE BATALHA SOBREIRA DA SILVA** \\ ANA MARIA FALCÃo DE ARAGÃO***
}

\begin{abstract}
RESUMO
O objetivo deste trabalho é analisar as concepções dos professores de Ciências (Física, Química e Biologia) de duas escolas da educação básica, ensino médio, localizadas nos estados de São Paulo e Minas Gerais. A pesquisa apresenta resultados sobre como a História e Filosofia da Ciência é considerada pelos professores da área de Ciências. A motivação para tal trabalho se deve à importância da inserção do tema nas aulas de ensino médio e devido às discussões e estudos de uma disciplina do curso de Pós-Graduação em Ensino de Ciências e Matemática durante o primeiro semestre de 2019 na Universidade Estadual de Campinas. Este trabalho, de natureza qualitativa, está dividido em duas partes. Os dados da primeira e segunda parte foram obtidos através de um questionário composto de perguntas abertas. Em sua primeira parte, procurou-se investigar quem são os professores que ministram aula de Ciências (Física, Química e Biologia) nas escolas, apresentando o perfil dos professores participantes. Os dados obtidos permitiram conhecer: a formação dos professores, faixa etária, distribuição por sexo, tempo de experiência
\end{abstract}

\footnotetext{
* Doutorando em Ensino de Ciências e Matemática - Pecim - Unicamp, ant.marcos975@gmail.com

** Mestra em Ensino de Ciências e Matemática - Pecim - Unicamp, jo_sobreira@yahoo.com.br

*** Professora Titular da Faculdade de Educação - Unicamp, anaragao@terra.com.br
} 
como docente e se já fez pós-graduação. Na segunda é realizada a análise das respostas (concepções) dos professores sobre a importância da História e Filosofia da Ciência. Após a análise das respostas da segunda parte foi possível verificar que alguns professores discutem o tema História e Filosofia da Ciência em sala; a maioria considera importante o tema; nenhum deles participou de algum curso de formação contínua relacionado ao tema e, de forma unânime, gostariam de participar de um curso sobre a História e Filosofia da Ciência.

Palavras-chave: Professores de Ciências da Natureza. Formação de Professores. História e Filosofia das Ciências.

\begin{abstract}
The objective of this work is to analyze the conceptions of the professors of Sciences (Physics, Chemistry and Biology) of two schools of basic education, high school, located in states of São Paulo and Minas Gerais. The research presents results on how the History and philosophy of science is considered by the professors of sciences. The motivation for such work is due to the importance of the insertion of the subject in the high school classes and due to the discussions and studies of a Postgraduate course in Science and Mathematics teaching during the first semester of 2019 at the State University of Campinas. This work, of a qualitative nature, is divided into two parts. The data of the first and second part were obtained through a questionnaire composed of open questions. In its first part, we sought to investigate who are the teachers that teach Science (Physics, Chemistry and Biology) in schools, presenting the profile of the participating teachers. The data obtained allowed us to know: teacher training, age group, distribution by sex, time of experience as a teacher and whether or not she did postgraduate studies. In the second one the analysis of the answers (conceptions) of the teachers on the importance of History and Philosophy of Science is carried out. After analyzing the answers of the second part it was
\end{abstract}


possible to verify that some teachers discuss the theme History and Philosophy of Science in room; most consider the theme important; none of them participated in any ongoing training course related to the subject and, unanimously, would like to participate in a course on the History and Philosophy of Science. Keywords: Teachers of Natural Sciences. Teacher Training. History and Philosophy of Sciences.

\section{INTRODUÇÃO}

Quando se discute sobre o ensino de ciências (Física, Química e Biologia), temas como, por exemplo, perfil de professores, formação e falta de professores da área, entre muitos outros, sempre são debatidos, e um deles merece atenção: qual a concepção do professor de Ciências sobre a História e Filosofia da Ciência (HFC) e como vem sendo trabalhado o tema em sala de aula? Isso é justificável, pois muitas pesquisas apontam que a História e Filosofia da Ciência vendo sendo apresentada de maneira superficial e, em outros casos, não sendo trabalhada na educação básica e nos diversos cursos de formação. Isso causa um problema, pois pode transmitir ao estudante uma imagem de ciência exata, neutra e que não se torna necessário considerar sua dimensão histórica.

A HFC poderá exercer a função de ajudar o estudante a entender a natureza dos conceitos científicos, mostrando como foram desenvolvidas as diversas teorias e quais as contribuições de cada cientista para a definição dos diversos conceitos que estão sendo desenvolvidos durante as aulas. De acordo com Morin (2001) "o conhecimento das informações ou dados isolados é insuficiente. É preciso situar as informações e os dados em seu contexto para que adquiram sentido".

Nesse sentido, torna-se imprescindível que se utilize do contexto histórico a fim de promover um estudo mais atraente e significativo.

Fazer uso da História da Ciência como um recurso pedagógico é sinalizada nas diversas pesquisas como um dos recursos de 
grande importância em todos os níveis de ensino, como preconiza os Parâmetros Curriculares Nacionais para o Ensino Médio (PCNEM), no qual está citado especificamente sobre a Física:

"A Física percebida enquanto construção histórica, como atividade social humana, emerge da cultura e leva à compreensão de que modelos explicativos não são únicos nem finais, tendo se sucedido ao longo dos tempos, como o modelo geocêntrico, substituído pelo heliocêntrico, a teoria do calórico pelo conceito de calor como energia, ou a sucessão dos vários modelos explicativos para a luz. $\mathrm{O}$ surgimento de teorias físicas mantém uma relação complexa com o contexto social em que ocorreram". (BRASIL, 2000).

Já sobre Biologia, é mencionado:

"Elementos da história e da filosofia da Biologia tornam possível aos alunos a compreensão de que há uma ampla rede de relações entre a produção científica e o contexto social, econômico e político. É possível verificar que a formulação, o sucesso ou o fracasso das diferentes teorias científicas estão associados a seu momento histórico" ( BRASIL 2000, p. 14).

Embora observações específicas deste tipo sejam encontradas nos PCNs, apresentando um objetivo de desenvolver uma prática que vá além de uma retórica de resultados, não podemos dizer que este documento se comprometa, de realidade, com a projeto de uma abordagem contextual do Ensino de Ciências. É necessário ressaltar, também, que não se trata apenas de incluir uma abordagem dos processos de construção do conhecimento científico no Ensino de Ciências, mas de considerá-los no conjunto histórico, filosófico e educacional em que a prática científica tem lugar. Ou seja, não é o caso de enfocar-se simplesmente 
na participação de alunos e educadores em atividades simuladas de investigação científica, sem tratamento explícito e crítico das dimensões históricas e filosóficas envolvidas em tal estudo. Em relação à História da Química, nos Parâmetros Curriculares Nacionais para o Ensino Médio (BRASIL, 2000), ao tratar dos conhecimentos de química, preconiza-se que "A História da Química como parte do conhecimento socialmente produzido, deve permear todo o ensino de química, possibilitando ao aluno a compreensão do processo de elaboração desse conhecimento, com seus avanços, erros e conflitos". (BRASIL, 2000, p. 31).

Além dos PCNEM e também dos Parâmetros Curriculares Nacionais (PCN), vários autores, entre eles GIL-PÉREZ (2003) destacam a importância do contexto histórico das ciências ao se ensinar os diversos conceitos servindo como auxílio para entendimento da evolução das diversas teorias. Como aponta Castro e Carvalho (1992): "A introdução da dimensão histórica pode tornar o conteúdo científico mais interessante e mais compreensível exatamente por trazê-lo para mais perto do universo cognitivo não só aluno, mas do próprio homem, que, antes de conhecer cientificamente, constrói historicamente o que conhece”.

Em relação a importância do estudo dessa temática por parte dos professores, Matthews (1995) coloca:

Seria, no mínimo, esquisito imaginar um bom professor de literatura que não tivesse conhecimento dos elementos da crítica literária [...] Da mesma forma, também deve ser estranho imaginar um bom professor de ciências que não detenha um conhecimento razoavelmente sólido da terminologia de sua própria disciplina [...]; ou nenhum conhecimento dos objetivos muitas vezes conflitantes de sua própria disciplina [...]; ou mesmo nenhum conhecimento da dimensão cultural e histórica de sua disciplina. (MATTHEWS, 1995, p. 188). 
No entanto, um dos obstáculos relacionados ao uso desse e de qualquer outro recurso pedagógico diz respeito à formação dos professores, a qual deve proporcionar uma base sólida para estes, pois a utilização da História da Ciência requer professores preparados para o bom desenvolvimento da aula e o mais importante é que também saibam selecionar o material histórico (textos, biografias, vídeos etc.) que serão utilizados, a fim de que os objetivos sejam alcançados. Para Duarte (2004), "A utilização da História da Ciência na sala de aula, requer que os professores possuam uma formação que lhes permita fazer uma seleção de material histórico adequado ou mesmo a construção de materiais específicos para a situação de ensino-aprendizagem.

A formação inicial e contínua de professores da área de Ciências com ênfase na HFC é um dos grandes desafios das secretarias de educação e dos cursos de ensino superior em todo o país, pois como já citado anteriormente, a falta de professores e a formação adequada para ensinar HFC pode tornar-se um grande empecilho para a implementação de currículos que atendam ao tema.

A falta de professores graduados com formação específica nas áreas de Ciências, principalmente na de Física, é outro ponto de muito destaque. O censo INEP/MEC de 2007 (BRASIL, 2009) revela que $74,8 \%$ dos professores de Física não são graduados na área em que atuam. Esse quadro é apresentado na Tabela 01, que mostra o número de professores habilitados do ensino médio nas disciplinas de Física, Química, Matemática e Biologia.

Tabela 01: Número de professores graduados por área

\begin{tabular}{l|c|c|c}
\hline Disciplina & $\begin{array}{c}\text { Número de } \\
\text { Professores }\end{array}$ & $\begin{array}{c}\text { Professores } \\
\text { Graduados na área }\end{array}$ & $\%$ \\
\hline Biologia & 43.480 & 26.898 & 61 \\
\hline Física & 44.566 & 11.490 & 25 \\
\hline Química & 38.871 & 11.541 & 37 \\
\hline Matemática & 67.447 & 46.778 & 69 \\
\hline
\end{tabular}

Fonte: BRASIL (2009), p. 41 e 42 
Outro ponto que vale a pena salientar é que uma aula de Ciências (Física, Química e Biologia) que contemple a dimensão histórica e filosófica exigirá um tempo maior do professor no preparo das aulas, pois o mesmo terá que pesquisar e selecionar o material (textos, biografias, vídeos etc) que será utilizado, a fim de que os objetivos sejam alcançados.

Dada a relevância do tema, este trabalho tem como objetivo principal analisar as concepções dos professores de Ciências da Natureza sobre a HFC, sistematizando: você já trabalhou a HFC em algum conteúdo; como foi o estudo do tema na graduação; você tem e/ou já acessou a literatura sobre HFC; participa de cursos de capacitação, entre outros.

No desenvolvimento deste trabalho, optamos por dividi-lo em duas partes, as quais estão descritas na seção da Metodologia.

\section{METODOLOGIA}

A pesquisa está dividida em duas partes: na primeira parte é descrito o perfil dos professores participantes e, na segunda, a apresentação das respostas às questões e análise das concepções dos professores sobre a HFC. A pesquisa foi realizada com professores do estado de São Paulo e de Minas Gerais. Como instrumento de coleta de dados, utilizou-se o questionário, constituído de perguntas abertas. Participaram da pesquisa 12 professores e os resultados da investigação estão na seção a seguir.

\section{ANÁLISE DOS DADOS E RESULTADOS}

\section{Primeira parte: Perfil dos professores}

Para a apresentação dos dados e resultados dos professores investigados, foram considerados os seguintes pontos: formação destes professores, faixa etária, distribuição por sexo, tempo de experiência como docente e se já fez pós-graduação.

Em relação à formação dos professores investigados, verifica-se que dos 12 professores de nossa amostra, 3 (25,0 \%) 
são formados em Química, 4 (33,4 \%) são formados em Física e 5 formados em Biologia, representando 41,6 \%. Esses resultados estão ilustrados na Figura 01.

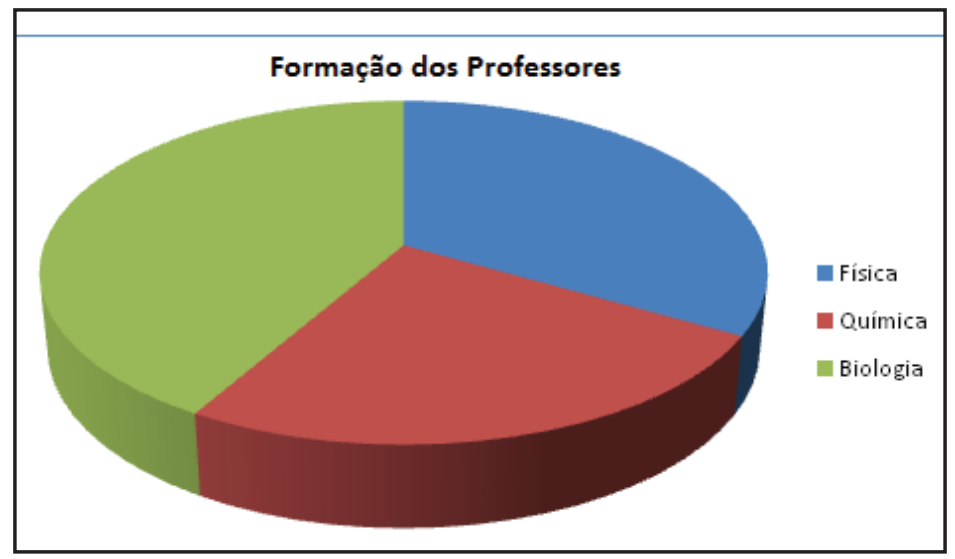

Figura 01: Formação dos professores investigados.

Em relação à distribuição dos professores por sexo verifica-se que a maioria é do sexo masculino, apresentado um total de $75 \%$. Este é um dado interessante, pois mostra o interesse de professores do sexo masculino na área de ciências da natureza. Um resultado bem próximo também foi encontrado em uma outra pesquisa realizada com professores da área de ciências de colégios públicos e privados de São Paulo, apresentando um número bem superior de professores do sexo masculino $(83 \%)$. Isto permite concluir uma maioria masculina trabalhando na área de ciências (Física, Química, Biologia).

$\mathrm{Na}$ análise da distribuição dos professores por faixa etária encontramos 9 deles com idade entre 42 e 60 anos, o que corresponde a $75 \%$. Vale destacar que encontramos 6 destes com idade igual ou acima de 52 anos., Encontra-se que 34,5\% dos professores estão com idade entre 51 e 55 anos, 10,3\% entre 46 e 50 anos e aproximadamente $13 \%$ dos professores estavam entre 36 e 40 anos e com a mesma porcentagem para a faixa 
etária de 26 a 30 anos. Um fato destacado por ele é que apenas $3,4 \%$ dos professores pesquisados estão na faixa etária com idade inferior a 25 anos. Isso, segundo o autor, mostra a ausência de recém-formados trabalhando na rede: ou os recém formados preferem fazer pós-graduação ou isso possivelmente seja um reflexo do desinteresse dos jovens pela área das ciências na cidade de Ribeirão Preto e no Brasil nos últimos anos.

Outro ponto investigado relaciona-se com o tempo de magistério (experiência como docente). Os resultados encontrados estão representados na Tabela 02.

Tabela 02: Tempo de magistério

\begin{tabular}{c|c|c}
\hline \multicolumn{3}{c}{ Tempo de magistério dos professores pesquisados } \\
\hline Entre 1 e 10 anos & 3 & $25 \%$ \\
\hline Entre 11 e 20 anos & 0 & $0 \%$ \\
\hline Entre 21 e 30 anos & 5 & $41,6 \%$ \\
\hline Entre 31 e 40 anos & 4 & $33,4 \%$ \\
\hline
\end{tabular}

Fonte: dos autores

O último ponto procura investigar se os professores possuem curso de pós-graduação. Os resultados obtidos estão representados no gráfico da Figura 02.

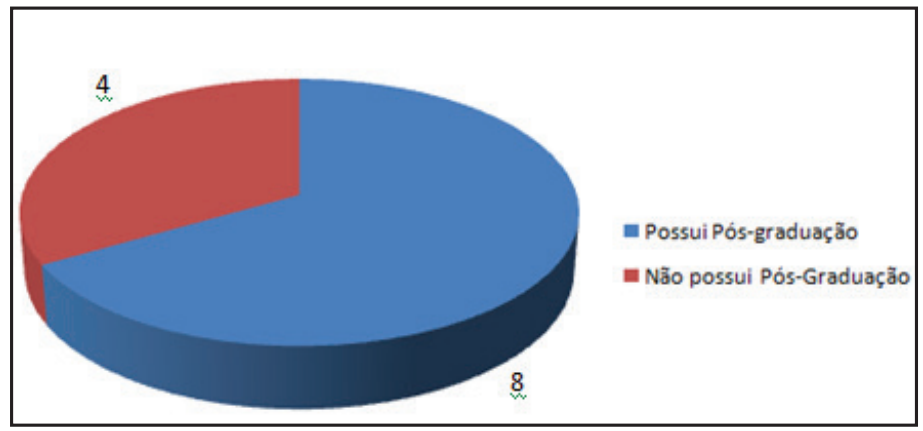

Figura 02: Relação entre participação e não participação em cursos de Pós-Graduação 
Vale destacar que dentre os que não possuem pós-graduação, um respondeu que já realizou um curso de especialização. Esse resultado é bastante significativo, pois a procura por cursos (formação contínua) pode ajudar o professor na melhoria de suas práticas pedagógicas, na busca de uma formação mais ampla e eficaz. Vale destacar que alguns dos cursos de pós-graduação citados pelos professores são em área diversas e outros não mencionaram o curso de pós.

Após a investigação inicial do questionário, também procurou-se saber se sobre material didático e todos os professores que responderam a pesquisa afirmam que faz uso do livro didático e/ou apostilas em suas aulas.

\section{Segunda parte: Concepções de Professores sobre a HFC}

Passaremos agora para a análise dos dados e resultados da segunda parte da pesquisa. As questões referem-se sobre as concepções dos professores sobre o tema História e Filosofia das Ciências da Natureza. Para manter o anonimato dos professores participantes, eles serão designados por P1, P2, P3, P4, P5, P6, P7, P8, P9, P10, P11 e P12. A letra P é a abreviação para Professor.

Questão 1: Você considera importante trabalhar a HFC em suas aulas? Comente.

Como resultado, todos os professores responderam "SIM" a esta questão. Para alguns a Ciência é uma construção histórica e incorpora e reflete o contexto social, econômico e cultural. Os excertos a seguir mostram algumas das respostas apresentadas pelos professores.

Acho muito importante trabalhar a História e Filosofia das Ciências como forma de contextualizar os conteúdos que estão sendo trabalhados. Também, creio que a História e Filosofia das Ciências ajudam os alunos a entenderem que os conhecimentos científicos não são estáticos. (P1). Sim, considero importante. Acredito que contextualizar o desenvolvimento da ciência sob uma perspectiva histórica , dá uma amplitude ao conhecimento. A abordagem histórica 
influencia e sofre influências das circunstâncias sociais, econômicas e culturais, por isso, acho tão importante a contextualização histórica. (P2).

Com certeza! Penso que a Filosofia atua na Ciência para especificar os métodos de estudo, a partir de dados de observação, para a justificativa da teoria. Precisamos instigar nossos alunos à pensar e a indagar. Assim, essas disciplinas podem contribuir para construir um aluno crítico, autônomo! (P3).

Sim, mas infelizmente percebo que são poucos os alunos que se interessam, chegando as vezes a questionar por exemplo: Por que eu preciso conhecer a evolução dos Modelos Atômicos? Por que você não fala só do atual? A mesma coisa com a evolução da Tabela periódica ou descoberta dos primeiros medicamentos. (P6).

Sim, acho importante o aluno tem que se dimensionar historicamente no processo da educação. Como exemplo a gente pode citar o trabalho do Thomson ao descobrir o elétron, o seu aluno Rutherford fez a descoberta do próton e em seguida o aluno do Rutherford, Chadwick, descobriu o nêutron. O processo é importante, eu acho, e vale a pena. (P12).

Verifica-se nas falas dos professores que todos consideram importante a HFC durante o desenvolvimento do conteúdo em suas aulas. Interessante destacar que, na fala do professor P6, ele cita o desinteresse de alguns alunos em relação à contextualização de alguns temas e, ao mesmo tempo, em contradição o P12 considera importante o processo de dimensão histórica e cita como exemplo a evolução dos modelos atômicos e diz que vale a pena o trabalho contextualizado em sala de aula. Esse é um ponto que precisa de discussão e fica a pergunta: como lidar e/ou estimular o interesse dos alunos para a HFC nos diversos temas das Ciências? 
Questão 2: Como é veiculado sobre a História e Filosofia das Ciências nos livros e/ ou apostilas adotados nas escolas que trabalham?Como são apresentados os cientistas e suas descobertas?

Com relação a esta questão, encontramos que a maioria dos professores declararam que a HFC é apresentada de maneira bem resumida, em pequenos textos, de forma superficial. Apenas um professor (P3) afirma que o livro adotado não aborda a parte histórica. A seguir transcrevemos as respostas dadas por quatro professores participantes:

Os cientistas e suas descobertas são apresentados de modo muito sucinto e sem muito destaque, em geral como nota de rodapé. (P1).

As questões voltadas à História e Filosofia das Ciências encontram-se diluídas nos conteúdos, ou mesmo em box específicos, apresentando a imagem do cientista e uma breve biografia. (P4).

História e Filosofia quase não é mencionado. Quando são, é par introduzir um assunto, mas não trabalhando num contexto mais abrangente. Os cientistas aparecem como seres iluminados, que descobrem como que por mágica. (P5).

O livro adotado sempre que possível cita fatos históricos: datas, nome do cientista e a sua descoberta, mas raramente fala como se chegou a essa descoberta. (P6).

Percebemos pelas respostas dos professores que os livros e apostilas apresentam poucas citações sobre a HFC se limitando a biografias, fotos e datas dos cientistas. Isto é bastante preocupante, pois a ausência desse recurso pode ser uma das causas para o não uso da temática em sala de aula e pode aumentar ainda mais o desinteresse dos alunos nas discussões sobre o tema.

Questão 3: Você já trabalhou a HFC em algum conteúdo em sala de aula? Se sim, qual foi o tema (conteúdo) da aula?

As respostas obtidas estão apresentadas no quadro a seguir. 
Quadro 01 - Respostas dadas à questão 3.

\begin{tabular}{|c|c|c|}
\hline Professor & $\begin{array}{c}\text { Trabalha HFC em } \\
\text { conteúdo na sala de } \\
\text { aula }\end{array}$ & Qual o tema \\
\hline P1 & Sempre que possível. & $\begin{array}{l}\text { - Física Moderna-História de Eins- } \\
\text { tein e o contexto social e histórico } \\
\text { em que viveu. }\end{array}$ \\
\hline P2 & Sim. & $\begin{array}{l}\text { - História da Saúde Pública no Brasil } \\
\text { - Tema: Doenças. } \\
\text { - Projeto Manhathan - Tema Áto- } \\
\text { mos. }\end{array}$ \\
\hline P3 & Sim. & $\begin{array}{l}\text { - Leis da Natureza - Medidas de } \\
\text { Astronomia. } \\
\text { - Física: Movimentos (Aristóteles, } \\
\text { Arquimedes). Inércia - Leis de } \\
\text { Newton. }\end{array}$ \\
\hline P4 & Sim & $\begin{array}{l}\text {-Genética, evolução, biotecnologia } \\
\text { e outros. }\end{array}$ \\
\hline P5 & Sim & $\begin{array}{l}\text { Em Biologia, o tema de Seleção } \\
\text { Natural pode ser relacionado aos } \\
\text { grandes avanços científicos na me- } \\
\text { tade do século XIX, relacionando } \\
\text { inclusive com o tema da Eugenia. }\end{array}$ \\
\hline P6 & Sim. & Química Orgânica. \\
\hline P7 & Não. & ---------------- \\
\hline P8 & Várias vezes. & $\begin{array}{l}\text { Ensino da Evolução, descoberta do } \\
\text { DNA, desenvolvimento das vacinas } \\
\text { e outros. }\end{array}$ \\
\hline P9 & Sim. & Energia Nuclear. \\
\hline P10 & Sim. & $\begin{array}{l}\text { Trabalhei o livro "A Filosofia da } \\
\text { Ciência" do Rubem Alvez. }\end{array}$ \\
\hline P11 & Sim. & Gravitação e Astronomia. \\
\hline P12 & $\begin{array}{l}\text { Sempre que possível } \\
\text { dou entrada historica- } \\
\text { mente no assunto. }\end{array}$ & $\begin{array}{l}\text { Termodinâmica: Joule e o equivalen- } \\
\text { te mecânico do calor. }\end{array}$ \\
\hline
\end{tabular}

Fonte: dos autores 
Observa-se que todos os professores trabalham a HFC durante o desenvolvimento de algum conteúdo em suas aulas. Apenas um responde que não. A resposta do professor P12 chamam a atenção, pois, ao final ele complementa que os alunos se interessaram bastante pelo tema, após a apresentação histórica sobre James Prescott Joule. Nas demais respostas observamos que os temas em que trabalham a HFC são variados e de grande relevância para a contextualização e discussão em sala de aula.

Questão 4: No seu curso de graduação você teve a disciplina HFC? Sim on Não? Se sim, como foi trabalhado a disciplina no curso? Comente.

Com relação a esta questão, oito professores responderam "Não". Interessante salientar que o professor P7 que respondeu que não trabalha a HFC nos seus temas em sala (ver quadro acima) é um dos que respondeu que não cursou nada da disciplina na graduação. E os professores P1, P3, P4 e P10 responderam que tiveram HFC no curso de graduação. Sobre como foi trabalhado a disciplina no curso, selecionamos três respostas:

Sim. Pelo que me lembro os alunos fizeram seminários sobre diferentes personagens (cientistas). (P1).

Sim. De forma muito acadêmica e pouco prática ou envolvente. (P10).

Sim. As disciplinas possibilitaram uma maior reflexão sobre os conteúdos trabalhados, tornando-os significativos. (P4).

Questão 5: Você conhece e/ ou acessa frequentemente a literatura com textos publicados sobre a História e Filosofia no ensino de ciências? Sim on Não?Se sim, qual revista e/ ou site você pesquison?

Seis professores responderam que não conhecem e não acessam material sobre HFC, correspondendo a 50\% dos investigados. Os outros seis professores responderam que acessam os 
seguintes materiais: Química Nova na Escola, Revista Fapesp, publicações diversas (leitura independente), Cadernos de História e Filosofia da Ciência - Unicamp. Revista Brasileira de História da Ciência pelo site, site ciência hoje para crianças e o outro professor acessa sites como a Wikipédia e artigos publicados na Sociedade Brasileira de Física.

Questão 6: Você já fez algum de curso de capacitação de professores sobre o tema História das Ciências?

Em relação à participação em cursos de capacitação (aperfeiçoamento profissional) sobre o tema HFC, verificamos que nenhum professor participou de cursos dessa temática.

Questão 7: Você gostaria de participar de algum curso de formação continuada em relação ao tema HFC?

Em contraposição às respostas da questão anterior, aqui todos os professores responderam "SIM", com destaque para as respostas dos professores P4, P10 e P12.

Sim, muito me interessa. (P4).

Sim, sem dúvidas, (P10).

Adoraria! Tenho muito interesse, principalmente no estudo da HFC sobre Ondas eletromagnéticas e estudo da Luz. (P12).

Nesse sentido, a LDB (BRASIL, 1996, p. 21) em seu Art. 67, Inciso II, estabelece que "os sistemas de ensino promoverão aperfeiçoamento profissional continuado, inclusive com licenciamento periódico remunerado para esse fim". Ainda segundo essa Lei (p. 26), em seu Art. 87, parágrafo $3^{\circ}$, Inciso III, “Cada Município e, supletivamente, o Estado e a União, deverá realizar programas de capacitação para todos os professores em exercício, utilizando também, para isto, os recursos da educação a distância”. 
Segundo MEC (2008, p.):

Cursos de aperfeiçoamento profissional em Física e em todas as demais áreas podem contribuir como complemento da formação inicial adquirida na graduação e proporcionar troca de experiências entre os professores em relação ao uso de novas abordagens de ensino, a fim de promover melhoria e aperfeiçoamento do corpo docente.

Um aspecto preocupante em nosso entender reside no fato de nunca nenhum professor ter realizado cursos de formação continuada (aperfeiçoamento) em relação à HFC. Isso pode ser resultado de alguns fatores, como: falta de tempo para participação em cursos; não oferta de cursos pelas secretarias de educação e entidades de ensino superior; ou até mesmo pelo desinteresse dos professores.

\section{CONSIDERAÇÕES FINAIS}

Este trabalho teve por objetivo analisar as concepções dos professores de Ciências (Física, Química e Biologia) de duas escolas de ensino médio. Inicialmente foi necessário conhecer o perfil dos professores participantes para uma melhor análise dos dados. Os resultados sobre o perfil foram interessantes, pois a maioria dos professores são formados na área em que atuam; a maioria possui curso de pós-graduação; 75\% dos professores possuem bastante experiência como docentes e oito deles já cursou uma pós-graduação.

$\mathrm{Na}$ segunda parte do trabalho foi feita a análise das respostas dos professores em relação à HFC e, apesar da maioria dos professores não terem em seu material didático sobre o tema e de não terem tido na grade da graduação alguma disciplina, eles trabalham em suas aulas a História das Ciências nos mais diferentes conteúdos da Física, Química e a Biologia. 
Outro ponto preocupante diz respeito sobre a forma simplista como os materiais didáticos abordam sobre a HFC e, alguns professores dizem fazer uso de sites que podem trazer informações não confiáveis e menos relevantes. Em contrapartida a essa concepção sobre as fontes (literatura), os professores não citam importantes veículos de circulação internacional, conforme destacado por Godoi, Figueirôa (2004). As autoras acrescentam que a literatura na área é bem ampla e como exemplos será colocado após as referências, alguns links de textos para que se possam aprofundar o tema.

A resposta à questão 6 nos deixa preocupados em relação à participação em cursos de formação continuada (aperfeiçoamento profissional) em que nenhum dos professores jamais fizeram algum curso sobre o tema HFC. O mais interessante em destacar é que todos os professores gostariam de participar de cursos de formação com discussões sobre a HFC.

E, por fim, gostaríamos de destacar uma última questão, a qual não foi colocada na análise dos dados, pois tinha o seguinte questionamento: Você gostaria de faz̧er alguma observação, comentário final sobre o tema investigado? E com as respostas dos professores participantes finalizamos este trabalho de pesquisa:

- P11: Acho o tema muito relevante, mas não me sinto capaz de trabalhá-lo, assim como falta tempo disponivel para tal.

- P12: Acho de fundamental importância que seja implementado na grade curricular do Ensino Médio esse tema sobre História e Filosofia da Ciência. O aluno fica engajado e tem um maior aproveitamento das aulas. Precisa urgentemente implementar o estudo da História da Ciência, com a ajuda de outras disciplinas da educação básica.

Nesse sentido, julgamos que o recurso didático HFC contribui para um trabalho crítico e contextualizado, capaz de auxiliar o professor e estudantes para um aprendizado mais sólido e eficaz. 


\section{REFERÊNCIAS}

BRASIL, Ministério da Educação, Secretaria de Educação Média e Tecnológica. Parâmetros Curriculares Nacionais: Ensino Médio. Brasília: Ministério da Educação, 2000.

BRASIL, Conselho Nacional de Educação. Lei de Diretrizes e Bases da Educação Nacional - LDB nº 9394/96. Brasília, DF, 1996.

BRASIL. Ministério da Educação. Instituto Nacional de Estudos e Pesquisas Educacionais Anísio Teixeira. Censo da Educação Superior de 2009. Brasília: Ministério da Educação, 2009.

Revista Brasileira da Educação Profissional e Tecnológica / Ministério da Educação, Secretaria de Educação Profissional e Tecnológica. v. 1, n. 1, (jun. 2008 - ). Brasília: MEC, SETEC, 2008.

CASTRO, Ruth Schmitz de; CARVALHO, Anna Maria Pessoa de. História da ciência: Investigando como usá-la num curso de segundo grau. Florianópolis, Cad. Cat. Ens. Física, v. 9, n. 3, p. 225-237, 1992.

DUARTE, Maria da Conceição. A história da ciência na prática de professores portugueses: implicações para a formação de professores de ciências. Ciência \& Educação (Bauru), v. 10, p. 317-331, 2004.

DE CASTRO, Ruth Schmitz; DE CARVALHO, Anna Maria Pessoa. História da ciência: investigando como usá-la num curso de segundo grau. Caderno Brasileiro de Ensino de Física, v. 9, n. 3, p. 225-237, 1992.

GIL-PÉREZ, D. et al. A educação científica e a situação do mundo um programa de atividades dirigido a professores. Ciência \& Educação, v. 9, n. 1, p. 123-146, 2003 https://doi.org/10.1590/S1516-73132003000100010

GODOI, L. C.; FIGUERÔA, S. F.M. Dois pesos e duas medidas: uma proposta para discutir a natureza do sistema de unidades de medida da sala de aula.

Caderno Brasileiro do Ensino de Física, v. 25, n. 3, p. 523 - 545, dez 2008.

LIDIANY, C. de O.; DE MENDONÇA FIGUEIRÔA, Silvia Fernanda. Dois pesos e duas medidas: uma proposta para discutir a natureza do sistema de unidades de medida na sala de aula. Caderno Brasileiro de Ensino de Física, v. 25, n. 3, p. 523-425, 2008. 
MATTHEWS, Michael S. História, filosofia e ensino de ciências: a tendência atual de reaproximação. Caderno Brasileiro de Ensino de Física, v. 12, n. 3, p. 164-214, 1995.

MORIN, Edgar. Os sete saberes necessários à educação do futuro. 3. ed. São Paulo: Cortez, 2001.

QUIRINO, W.G.; LAVARDA, F.C. Projeto experimentos de Física para o Ensino Médio com materiais do dia a dia. Caderno Catarinense de Ensino de Física, v. 18, n. 1, p. 117-122, abr. 2001. 